\title{
General Practitioners' Current and Emerging Views about Pay for Performance Schemes
}

\author{
Giorgia Rotundo ${ }^{1}$, Marianna Mauro ${ }^{2}$ and Monica Giancotti*2 \\ ${ }^{1}$ Department of Legal, Historical, Economic and Social Sciences, Magna Graecia University, Catanzaro, Italy \\ ${ }^{2}$ Department of Clinical and Experimental Medicine, Magna Graecia University, Catanzaro, Italy \\ *Correspondence to: Monica Giancotti, Department of Clinical and Experimental Medicine, Magna Graecia University, Catanzaro, Italy; Tel: +39 0961 3694374; \\ E-mail: mgiancotti@unicz.it
}

Received: July 30, 2018; Accepted: August 04, 2018; Published: August 16, 2018

\begin{abstract}
In many healthcare system, General Practitioners play a crucial role for those requiring medical services. Using financial incentives to directly reward "performance" and "quality" is a new compensation method developed in more countries.

One of the biggest examples of payment for performance is the Quality and Outcome Framework (QOF) started in United Kingdom in 2004.

Despite the proliferation of these different programs across the world, the evidence to support their use is widely debated.

The main aim of this study was to provide an overview about different General Practitioners perceptions related to the design and implementation of pay-for-performance initiatives. To achieve this aim we reviewed recent studies published from 2004, with a particular focus on general practitioners' views about pay for performance remuneration schemes.
\end{abstract}

The results suggest that despite pay for performance is successfully accepted, in few cases does appear to have had a negative impact on some aspects of medical professionalism, and reduced clinical autonomy.

Keywords: Pay for performance; General practitioners; primary care; financial incentives

\section{Introduction}

In several healthcare systems, General Practitioners (GPs) are the primary contact for those requiring health care and act as gatekeepers to hospital services. Therefore, they play a vital role to healthcare system performance.[1]

The use of different ways of paying primary care physicians in an attempt to increase quality of care, including the use of financial incentives to directly reward "performance" and "quality", is increasing in many countries.[2]

The rationale of pay for performance schemes is based on the premise that income is a key motivating factor for GPs. [1]

One of the biggest examples of payment for performance anywhere in the world is the Quality and Outcome Framework (QOF), a new contract for family practices in United Kingdom (UK).[3]

The scheme attached financial rewards for meeting 146 quality targets in relation to clinical, organizational, and patient experience indicators and in 2006 it was modified to 135 indicators. [4]

QOF payments represented up to 20\% of GPs' income in the first year of its introduction.[5]

Despite the proliferation of $\mathrm{P} 4 \mathrm{P}$ programs, the evidence to support their use is still inconclusive. $[6,7]$ one of the reasons may be the differences between $\mathrm{P} 4 \mathrm{P}$ programs. Incentives in current programs vary in terms of number and type of indicators, professional standards and quality domains (clinical care, patient experience, organization of care). $[5,8]$

The size of the incentive and the unit of assessment in $\mathrm{P} 4 \mathrm{P}$ programs can influence their effectiveness. [9]

The intended consequences of the new contractual arrangements were to reward quality of care rather than numbers of registered patients, to improve data capture and care processes, and to improve patient outcomes and doctors' working conditions. $[3,10]$

Financial incentives can change behavior and policy-makers have sought to improve quality by making more payments to health professionals dependent on performance against predetermined standards.[11]

The main aim of this study was to provide an overview about different General Practitioners perceptions related to the design and implementation of pay-for-performance initiatives. To achieve this aim we reviewed recent studies published from 2004, with a particular focus on general practitioners' views about pay for performance remuneration schemes.

\section{GPs views toward quality based compensation scheme}

Despite perceptions of the negative consequences on workload and autonomy before the introduction of the scheme, some authors 
reported that GPs were more positive than they had anticipated on its impact on the quality of care. About that, Whalley et al., [12] evaluated physicians' views in United kingdom of their working life and quality of care before and after the new contract and showed that overall job satisfaction increased, from 4.58 out of 7 in 2004 to 5.17 in 2005; the average worked hours reported decreased from 44.5 to 40.8 and average income rose from $£ 73400$ in 2004 to $£ 92600$ in 2005, contrary to what they had anticipated before the introduction of the QOF.

Also Beckman et al.,[13] demonstrated that despite primary care physicians were skeptical, after the introduction of the new remuneration scheme created by United States Excellus BlueCross BlueShield and its individual practice association (IPA) partner, the Rochester Individual Practice Association (RIPA), were positive influenced on making improvements in quality, satisfaction, and practice efficiency.

Attitudes towards the contract were largely positive, McDonald et al.,[14] explored the impact of financial incentives for quality of care on practice organization, clinical autonomy, and internal motivation of doctors and nurses working in primary care over a five month period after the introduction of the contract. They showed that there was an increase in the use of templates to collect data on quality of care, although discontent was higher in the practice with a more intensive surveillance regimen. Nurses expressed more concern than doctors about changes to their clinical practice but also appreciated being given responsibility for delivering on targets in particular disease areas.

Physicians and nurses interviewed by Campbell et al., [10] in 22 nationwide representative practices across England between February and August 2007 believed that the objectives of the scheme were achieved in terms of improvements in the specific processes for the patient's care and their income, as well as better data acquisition. However, it also led to side effects, such as the emergence of a double QOF-patient program in consultations, a decline in personal / relational continuity of care between doctors and patients and resentment by group members who do not benefit of payments.

In addition, GPs and practice managers described a sense of decreased clinical autonomy and loss of professionalism.[15]

Participants to the study by Maisey et al., [16] reported substantial improvements in teamwork and in the organization, consistency and recording of care for conditions incentivized under QOF scheme, but not for non-incentivized activities and patients' concerns may receive less clinical attention.

A Scottish study by Feng et al., [17] investigated whether and how a change in performance-related payment motivated GPs and evaluated the effect of increases in the performance thresholds required for maximum payment under the QOF. They found that the increase in the maximum performance thresholds increased GPs' performance by $1.77 \%$ on average. Low-performing GPs improved significantly more (13.22\%) than their high-performing counterparts (0.24\%).
Kirschner and Grol, [18]conducted a qualitative study in 29 general practices in the Netherlands in order to explore general practices' experiences with pay-for- performance in primary care about feasibility, feedback and the bonus and spending of the bonus. They found that the feasibility of the program was questioned due to the substantial time investment. The feedback on clinical care, practice management and patient experience was mostly discussed in the team, and used for improvement plans. The bonus was considered a stimulus to improve quality of care and was mainly spent on new equipment or team building.

A key factor in designing pay-for-performance programs is determining what entity the incentive should be awarded to individual clinicians or to groups of clinicians working in teams. The study of Greene et al., [19] examined primary care clinicians' perceptions of a team-based quality incentive awarded at the clinic level. Clinicians reported the strengths of the clinic-based quality incentive were quality improvement for the team and less patient "dumping," or shifting patients with poor outcomes to other clinicians.

Allen et al., [1] used data on 1920 GPs in order to verify correlation between changes in GPs' job satisfaction before and after the introduction of the QOF and the proportion of their income. They found no significant effects of $\mathrm{P} 4 \mathrm{P}$ exposure on overall job satisfaction .The level of exposure to P4P does not harm job satisfaction or other aspects of working lives such as: working hours; intentions to quit; life satisfaction.

Contrary, Krauth et al.,..[20]showed that among 2493 general practitioners (GPs) in Lower Saxony the participation rate to P4P increased from $28 \%$ (at a bonus of $2.5 \%$ ) to $50 \%$ (at a bonus of $20 \%$ ).

\section{Discussion}

There has been a growing interest in the use of financial incentives in order to improve quality of healthcare.[21]

In this article, the authors reviewed different GPs perceptions relate to the design and implementation of pay-for-performance initiatives.

A crucial element for the successful implementation of $\mathrm{P} 4 \mathrm{P}$ is to gain acceptance with health care providers. [20]

The impact of these new remuneration schemes is also likely to be influenced by a number of other factors such as levels of physician understanding of the purpose and involvement in the development of the scheme; the nature, appropriateness, and adequacy of measures used; the feasibility of implementation; and the magnitude of an incentive necessary to produce the behavioral change required to achieve targets. Other factors include the balance between team and individual incentives. [6, 22-24]

Most practices considered the bonus a stimulus to improve quality of care, in addition to compensation for their effort and time invested.[18]

Our study provides qualitative evidence that practices incentivized had made substantial changes in systems, and that the changes were focused on delivering improved care. 
Nevertheless, the efficiency of this additional payment is debated, and the need to implement target payment schemes is questionable because the relationship between pay and performance has not been well understood.[1]

This study suggests that despite pay for performance is successfully accepted, in few cases does appear to have had a negative impact on some aspects of medical professionalism, with a perception that it was, in part, responsible for GPs prioritizing their own pay rather than patients' interests and reduced clinical autonomy.

In order to convince GPs to participate in P4P, better evidence for the effectiveness of $\mathrm{P} 4 \mathrm{P}$ is required and program implementation must be well communicated and thoroughly discussed with health care providers.[20]

\section{References}

1. Allen T, Whittaker W, Sutton M (2017) Does the proportion of pay linked to performance affect the job satisfaction of general practitioners?.Social Science \& Medicine. 1;173: 9-17. [crossref]

2. Scott A, Sivey P, Ait Ouakrim D, Willenberg L et al. (2011) The effect of financial incentives on the quality of health care provided by primary care physicians. In Cochrane Database of Systematic Reviews. John Wiley\&Sons,Ltd. Retrieved from http://onlinelibrary.wiley.com/doi/10.1002/14651858.CD008451.pub2/abstract [crossref]

3. Martin Roland D. (2004) Linking physicians' pay to the quality of care - a major experiment in the United Kingdom. New England Journal of Medicine. 351: 144854.27;355(4): 375-84. [crossref]

4. Campbell S, Reeves D, Kontopantelis E, Middleton E et al. (2007) Quality of primary care in England with the introduction of pay for performance. New England Journal of Medicine. 12;357(2): 181-90.

5. Doran T, Fullwood C, Gravelle H, Reeves D,et al.(2006) Pay-for-performance programs in family practices in the United Kingdom. New England Journal of Medicine.

6. Rosenthal MB, Frank RG, Li Z, Epstein AM. (2005) Early experience with pay-forperformance: from concept to practice. Jama. 294(14): 1788-93. [crossref]

7. Petersen LA, Woodard LD, Urech T, Daw C, et al. (2006) Does pay-for-performance improve the quality of health care?. Annals of internal medicine. 145(4): 265-72. [crossref]

8. Campbell SM, Reeves D, Kontopantelis E, Sibbald B, et al. (2009) Effects of pay for performance on the quality of primary care in England. New England Journal of Medicine. 361(4): 368-78.

9. Kirschner K, Braspenning J, Jacobs JA, Grol R. (2012) Design choices made by target users for a pay-for-performance program in primary care: an action research approach. BMC Family Practice. 13(1): 25.

10. Campbell SM, McDonald R, Lester H. (2008) The experience of pay for performance in English family practice: a qualitative study. The Annals of Family Medicine. 6(3): 228-34. [crossref]

11. Chaix-Couturier C, Durand-Zaleski I, Jolly D, Durieux P (2000) Effects of financial incentives on medical practice: results from a systematic review of the literature and methodological issues. International Journal for Quality in Health Care. 12(2): 133-42. [crossref]

12. Whalley D, Gravelle H, Sibbald B (2008) Effect of the new contract on GPs' working lives and perceptions of quality of care: a longitudinal survey. $\mathrm{Br} \mathrm{J} \mathrm{Gen}$ Pract. 58(546): 8-14. [crossref]

13. Beckman H, Suchman AL, Curtin K, Greene RA (2006) Physician reactions to quantitative individual performance reports. American Journal of Medical Quality. 21(3): 192-9.

14. McDonald R, Harrison S, Checkland K, Campbell SM, et al. (2007) Impact of financial incentives on clinical autonomy and internal motivation in primary care: ethnographic study. Bmj. 334(7608): 1357.

15. Lester H, Matharu T, Mohammed MA, Lester D, et al.(2013) Implementation of pay for performance in primary care: a qualitative study 8 years after introduction. $\mathrm{Br} J$ Gen Pract. 63(611): e408-15. [crossref]

16. Maisey S, Steel N, Marsh R, Gillam S, et al. (2008) Effects of payment for performance in primary care: qualitative interview study. Journal of health services research \& policy. 13(3): 133-9. [crossref]

17. Feng Y, Ma A, Farrar S, Sutton M. (2015) The Tougher the Better: an economic analysis of increased payment thresholds on the performance of General Practices. Health economics. 24(3): 353-71.
18. Kirschner K, Braspenning J, Jacobs JA, Grol R. (2013) Experiences of general practices with a participatory pay-for-performance program: a qualitative study in primary care. Australian journal of primary health. 19(2): 102-6.

19. Greene J, Hibbard JH, Overton V. (2015) Large performance incentives had the greatest impact on providers whose quality metrics were lowest at baseline. Health Affairs. 34(4): 673-80. [crossref]

20. Krauth C, Liersch S, Jensen S, Amelung VE. (2016) Would German physicians opt for pay-for-performance programs? A willingness-to-accept experiment in a large general practitioners' sample. Health Policy. 120(2): 148-58. [crossref]

21. Christianson JB, Leatherman S, Sutherland K (2008) Lessons from evaluations of purchaser pay-for-performance programs. Medical Care Research and Review. 65(6_suppl): 5S-35S. [crossref]

22. Young GJ, White B, Burgess Jr JF, Berlowitz D, et al. (2005) Conceptual issues in the design and implementation of pay-for-quality programs. American Journal of Medical Quality. 20(3): 144-50. [crossref]

23. Town R, Kane R, Johnson P, Butler M (2005) Economic incentives and physicians' delivery of preventive care: a systematic review. American journal of preventive medicine. 28(2): 234-40. [crossref]

24. Fisher ES. (2006) Paying for performance-risks and recommendations. New England Journal of Medicine. 355(18): 1845-7.
Citation:

Giorgia Rotundo, Marianna Mauro and Monica Giancotti (2018) General Practitioners' Current and Emerging Views about Pay for Performance Schemes. J Clin Res Med Volume 1(2): 1-3. DOI: 10.31038/JCRM.1000107 